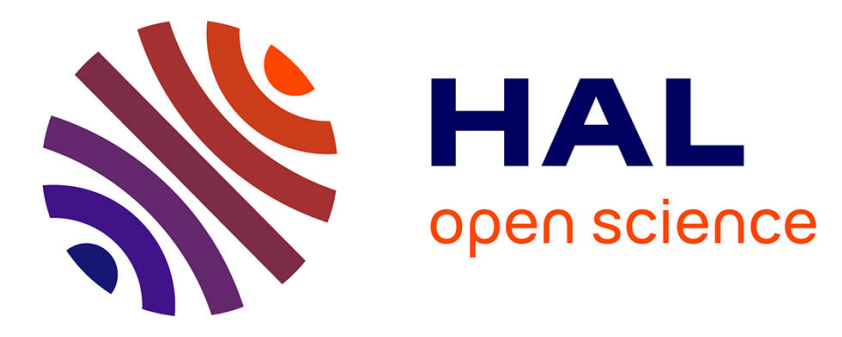

\title{
LIDAR altimeter conception for HERA spacecraft
}

Nicole Gomes Dias, Beltran Nadal Arribas, Paulo Gordo, Tiago Sousa, João

Marinho, Rui Melicio, António Amorim, Patrick Michel, Nicole G Dias, Beltran N Arribas, et al.

\section{- To cite this version:}

Nicole Gomes Dias, Beltran Nadal Arribas, Paulo Gordo, Tiago Sousa, João Marinho, et al.. LIDAR altimeter conception for HERA spacecraft. Aircraft Engineering and Aerospace Technology, 2021, 93 (6), pp.1018-1028. 10.1108/AEAT-12-2020-0300 . insu-03381691

\section{HAL Id: insu-03381691 https://hal-insu.archives-ouvertes.fr/insu-03381691}

Submitted on 17 Oct 2021

HAL is a multi-disciplinary open access archive for the deposit and dissemination of scientific research documents, whether they are published or not. The documents may come from teaching and research institutions in France or abroad, or from public or private research centers.
L'archive ouverte pluridisciplinaire HAL, est destinée au dépôt et à la diffusion de documents scientifiques de niveau recherche, publiés ou non, émanant des établissements d'enseignement et de recherche français ou étrangers, des laboratoires publics ou privés. 
PAPER - OPEN ACCESS

\section{HERA Mission LIDAR Altimeter Implementation}

To cite this article: Nicole G. Dias et al 2021 IOP Conf. Ser.: Mater. Sci. Eng. 1024012112

View the article online for updates and enhancements. 


\title{
HERA Mission LIDAR Altimeter Implementation
}

\author{
Nicole G. Dias ${ }^{1}$, Beltran N. Arribas ${ }^{1}$, Paulo Gordo ${ }^{1}$, Tiago Sousa ${ }^{3}$, João Marinho ${ }^{3}$, \\ Rui Melicio ${ }^{2}$, António Amorim ${ }^{1}$, Patrick Michel ${ }^{4}$ and NEO-MAPP Team ${ }^{5}$ \\ ${ }^{1}$ Faculdade de Ciências, Universidade de Lisboa, Lisboa, Portugal \\ ${ }^{2}$ IDMEC/LAETA, Instituto Superior Técnico, Universidade de Lisboa; ICT, \\ Universidade de Évora, Évora, Portugal \\ ${ }^{3}$ EFACEC, Aerospace Division, Leça Balio, Portugal \\ ${ }^{4}$ Université Côte d'Azur, Observatoire de la Côte d'Azur, CNRS, Laboratoire \\ Lagrange, Nice, France \\ ${ }^{5} \mathrm{~A}$ full list of NEO-MAPP authors appears at the end of the paper \\ Corresponding author: ruimelicio@gmail.com
}

\begin{abstract}
The Asteroid Impact \& Deflection Assessment (AIDA) is a collaboration between the NASA DART mission and ESA Hera mission. The aim scope is to study the asteroid deflection through a kinetic collision. DART spacecraft will collide with Didymos-B, while ground stations monitor the orbit change. HERA spacecraft will study the post-impact scenario. The HERA spacecraft is composed by a main spacecraft and two small CubeSats. HERA will monitor the asteroid through cameras, Radar, Satellite-to-Satellite doppler tracking, LIDAR, seismometry and gravimetry. In this paper is reported the first iteration on the LIDAR ENGINEERING MODEL ALTIMETER named HELENA. HELENA is a TOF altimeter that provides time-tagged distances and velocity measurements. The LIDAR can be used for support near asteroid navigation and provides scientific information. The HELENA design comprises a microchip laser and low noise sensor. The synergies between these two technologies enable developing a compact instrument for range measurements of up to $14 \mathrm{~km}$. Thermal-mechanical and radiometric simulations of the HELENA telescope are reported in this paper. The design is subjected to vibrational, static and thermal conditions, and it was possible to conclude by the results that the telescope is compliant with the random vibration levels, the static load and the operating temperatures.
\end{abstract}

\section{Introduction}

In the mid to late 1960s, the laser profiling and scanning systems were developed where the phased comparison and the pulse echo were the main measurement techniques. This technology began with the terrestrial cases and progressed to the airborne and space scenarios. In the last case, very powerful lasers have to be used to measure hundreds of kilometers, at least "100 times greater than those being measured form an airborne platform" [1]. Due to the reduced rate of measurement that a great laser pulse provided, the spaceborne missions were limited at the time. NASA has been the pioneer in developing laser profilers and scanners since 1970, and the first spaceborne altimeters were integrated in the Apollo missions (Apollo 15, 16 and 17) [2]. Several other missions were accomplished with different aims, such as study topographies, assess canopies, measuring distances, or support spacecraft navigation, from fly by to landing operations, making LIDAR a very versatile technology.

Low mass compact spacecraft missions to asteroids is an increasing trend, including small landing spacecraft. This fact tends to drive instrument design, namely miniaturization, and flexibility, 
maintaining its performance. New compact rangefinder technologies are therefore needed for future asteroid missions.

The AIDA mission is an effort between DART mission (NASA) and Hera mission (ESA). DART's goal is to cause and demonstrate the deflection of an asteroid using the kinetic impact, and Hera is to characterize the deflection caused by the impact. The target, called Dydimos- $\mathrm{B}$, is the small object from a binary Near-Earth Asteroid (NEA), Dydimos, and so LIDAR plays an important role allowing to map the asteroid and support spacecraft navigation.

HELENA is a Time of Flight (ToF) LIDAR altimeter that measure distances from HERA spacecraft to the asteroid, providing information for a 3D topographic mapping of the asteroid, and also reports the power of the received pulse being possible to calculate the target reflectivity. Most's measure operations will be performed at $14 \mathrm{~km}$ to $10 \mathrm{~km}$ of distance, and by the end of the mission, more hazardous operations will be performed, such as Fly byes or landing operations [3-5].

This work presents the design of the optical front end of the LIDAR, its radiometric calculations, optomechanical design, and mechanical simulations [3-5]. The LIDAR design comprises a microchip laser and a low noise sensor. The synergies between these two technologies enable developing a compact instrument for range measurements of up to $14 \mathrm{~km}$ with low power consumption and envelope. HELENA acquisition modes can be made in BURST or SINGLE mode. In the first mode, the instrument will output measurement at a configurable periodicity (maximum $10 \mathrm{~Hz}$ ), and in the second mode, HELENA will output only on measurement, with the value of the median of nine measurement samples [3]. HELENA will also periodically send a housekeeping packet with the equipment health information in both working modes. On the lowest power consumption mode, IDLE, only housekeeping data is available and all the front-end are switched off. The paper is structured as follows: Section 2 is about radiometric model. Section 3 presents the mechanical design. Section 4 presents the thermal-mechanical simulations. Finally, Section 5 outlines conclusions.

\section{Radiometric model}

To dimension the LIDAR, it is necessary to perform a radiometric analysis in its operational scenario. The LASER source for HELENA is currently being developed at the Faculdade de Ciências da Universidade de Lisboa (FCUL), and it is a diode-pumped, passively Q-switched Yb-Er Microchip Laser-targeting a $100 \mu \mathrm{J}$ pulse with a full-width half-maximum (FWHM) of $2 \mathrm{~ns}$ [3].

The radiometric budget allows the calculation of LIDAR front-end "received" energy as a function of emitted pulse energy taking into consideration the LIDAR specifications (e.g., LIDAR laser pulse energy, optical transmittance, optical aperture). The received pulsed energy, i.e., the relation between pulse energy sent and energy received at the Avalanche Photodiode (APD) is calculated by the LIDAR link equation given by:

$E_{r}=E_{t r} \tau_{r} \frac{A_{r}}{R^{2}} \frac{r_{s}}{\pi} O_{v}$

where $E_{r}$ is the echo pulse energy $(\mathrm{J}), E_{t r}$ is the transmitted laser-pulse energy $(\mathrm{J}), \tau_{r}$ is the receiver optics transmission, $A_{r}$ is the receiver telescope aperture area $\left(\mathrm{m}^{2}\right), r_{s}$ is the target surface reflectivity (assuming Lambertian), $O_{v}$ is the overlap between emitter and receiver, and $R$ is the distance from the LIDAR to the asteroid.

The peak power of the receiver signal $\mathrm{P}(\mathrm{W})$ is given by:

$P=\frac{0.94 \cdot E_{r}}{\Delta t}$

where $\Delta t$ is the FWHM of the gaussian pulse duration.

The requirements and specifications for the LIDAR radiometric calculations are given in the Table 1. 
Table 1. LIDAR system parameters

\begin{tabular}{|c|c|c|}
\hline \multicolumn{3}{|c|}{ System parameters \& mission requirements } \\
\hline Symbol & Value & Description \\
\hline $\mathrm{R}$ & $200 \mathrm{~m}$ to $14 \mathrm{~km}$ & $\begin{array}{l}\text { Variation of HERA probe distance during LIDAR } \\
\text { operation. }\end{array}$ \\
\hline \multicolumn{2}{|c|}{ LIDAR Receiver specifications } & $\begin{array}{l}\text { Asteroid albedo } \\
\text { DAR Receiver specifications }\end{array}$ \\
\hline$E_{\text {tr }}$ & $94 \mu \mathrm{J}$ & Transmitted laser pulse energy (after optics) \\
\hline$\tau_{\mathrm{r}}$ & 0.91 & Receiver optics transmission \\
\hline & $100 \mathrm{~mm}$ & Receiver telescope primary mirror diameter \\
\hline & $1.5 \mathrm{mrad}$ & Receiver FOV \\
\hline & Sensor responsivity & Sensor @M=20, 1550 nm":230*kV/Watt \\
\hline & $3.2 \mathrm{nW}$ & Sensor NEP \\
\hline & $6 \mathrm{~nm}$ & FWHM Spectral filter \\
\hline \multicolumn{3}{|r|}{ LIDAR emitter specifications } \\
\hline & $1 \mathrm{mrad}$ & Emitter FOV \\
\hline & $21 \mathrm{~mm}$ & Emitter aperture \\
\hline & $94 \mu \mathrm{J}$ & Transmitted laser pulse energy (after optics) \\
\hline & $2 \mathrm{~ns}$ & Laser FWHM \\
\hline & $29 \mathrm{~mm}$ & Edge distance between receiver and emitter \\
\hline
\end{tabular}

The returned peak power, along with the sensor's saturation limits and minimum detectable power (considering the solar background, sensor NEP, and $\mathrm{M}=20$ ), are presented in Figure 1.

The solar background was also considered a source of noise, and it can be mitigated by using an optical bandpass filter of $6 \mathrm{~nm}$ FWHM at the center of the laser wavelength.

The minimum detectable power is $4.1 \mathrm{nW}$ (considering the sensor NEP and the solar radiation background). According to the simulations, the LIDAR can detect signal for the mission operational distance value of $14 \mathrm{~km}$, even if the target surface has a 20 degree inclination. From the simulations, the telescope aperture and the optical bandpass filter were defined.

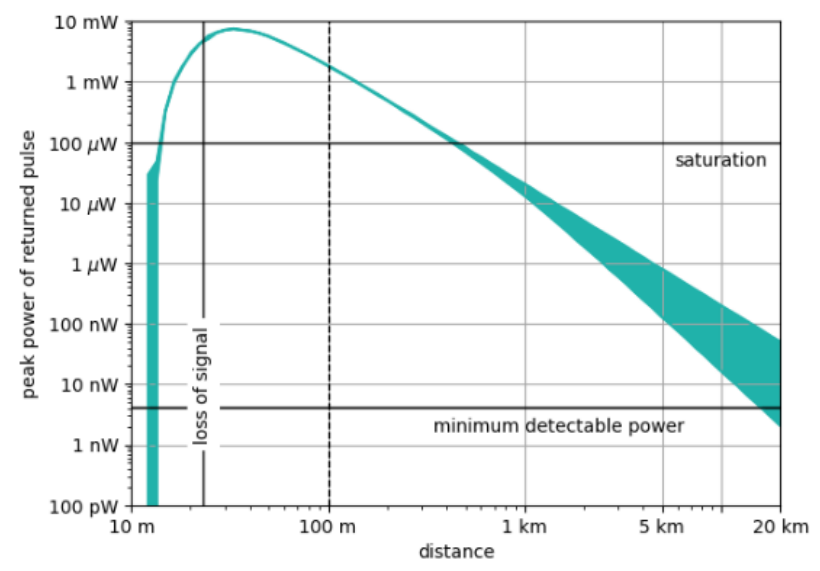

Figure 1. Detected peak power.

\section{Mechanical design}

The optical front-end optomechanics are composed of four main blocks: 1) the receiver; 2) the emitter, the 3) front-end electronics, and 4) the electronics box. The main mechanical material is AL6063-T6, and it was used in the majority of the mechanical parts. The receiver, emitter, and front-end electronics 
are assembled on the exterior of the spacecraft (LIDAR front end), and the electronics box (LIDAR electronics) is assembled in the satellite.

The receiver consists of telescope (Cassegrain design), refractive optics, and the sensor. The primary mirror is made of zerodur and has a $100 \mathrm{~mm}$ diameter. The receiver telescope is considered the most critical structure, from optical, mechanical, and thermal points of view, and therefore was the main subject of the thermal-mechanical simulations. The LIDAR front end is presented in Figure 2.

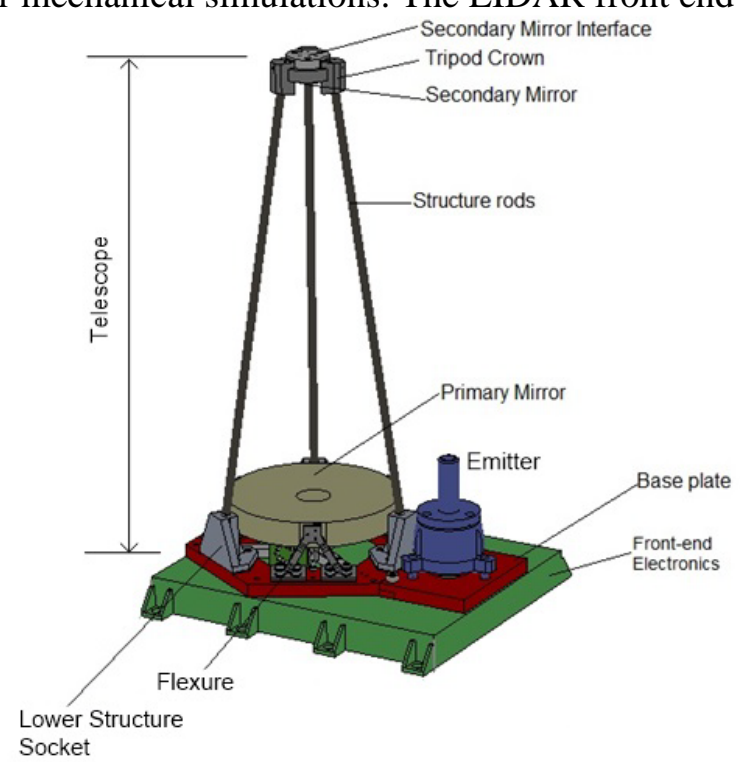

Figure 2. LIDAR mechanical design. 1) the receiver; 2) the emitter, and the 3) front-end electronics.

The emitter has a microchip laser followed by a beam expander and is assembled by the receiver's side. Both receiver and emitter are assembled on a base plate that, in turn, is assembled on the frontend electronics' enclosure. HELENA is a very compact instrument with $185 \mathrm{~mm}$ of length, $174 \mathrm{~mm}$ of width, and $320 \mathrm{~mm}$ of height.

\section{Thermal-mechanical simulations}

The thermal-mechanical simulations are divided into the vibrational, static, and thermal analysis. The software used to perform such studies was SolidWorks. The objective was to investigate the most critical component, the telescope, and assess the optical performance under different environmental conditions. The optical evaluation criterium was based on the optical tolerance analysis, that defined as $\mp 0.15 \mathrm{~mm}$ the maximum admissible displacement (secondary mirror to baseplate distance), and 干0.2 mrad the maximum admissible tilt of the secondary mirror. Two studies were made, namely: One that considers the upper telescope structural components were made of AL6063-T6. Other that considers the upper telescope structural components made of Titanium, as shown in Figure 3.

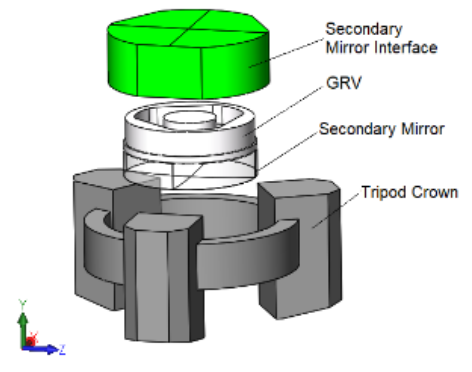

Figure 3. Upper components (simplified version). 


\subsection{Vibrational analysis}

The levels for the Random Vibration environment considered was from ARIANE 6. The preprocessing, analysis and post-processing were made with SolidWorks.

The finite element model presented a mesh with 15522 elements and 29115 nodes. It was only considered the first study case. The boundary conditions applied in this analysis are presented in Figure 4, where the structure is fixed at the base (Figure 4a) and a remote mass equivalent to the secondary mirror plus the other components that fix it to the crown (Figure 4b).

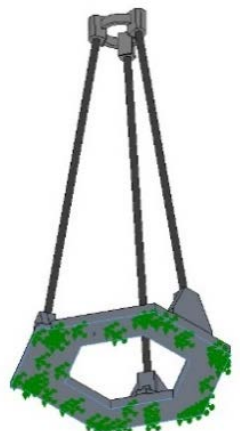

(a)

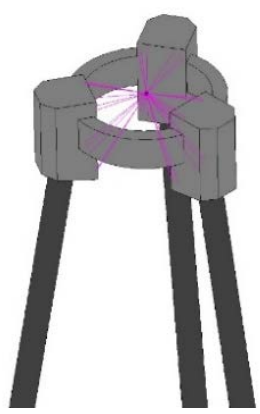

(b)

Figure 4. LIDAR structure boundary conditions: a) fixed base, b) remote mass.

The Power Spectral Density (PSD) is the variation of the acceleration for a given axis concerning the frequency. The results are given on the basis of a one sigma probability of the stresses to be under the maximum value, this means that the stress has a probability of $68 \%$ to be under the maximum value. To be more accurate, the maximum stress must be multiplied by 2 or 3 for a probability of $95 \%$ and $99 \%$, respectively. This gives for the von Mises stress, for the X-axis, a probability of $99 \%$ to be under $73.86 \mathrm{~N} / \mathrm{mm}^{2}$ which is considered an acceptable value.

A typical result is presented in Figure 5 and in Figure 6 for the X-axis. Figure 5 shows the von Mises stress distribution, and Figure 6 represents the total displacement felt by the telescope when subjected to the random vibration level.
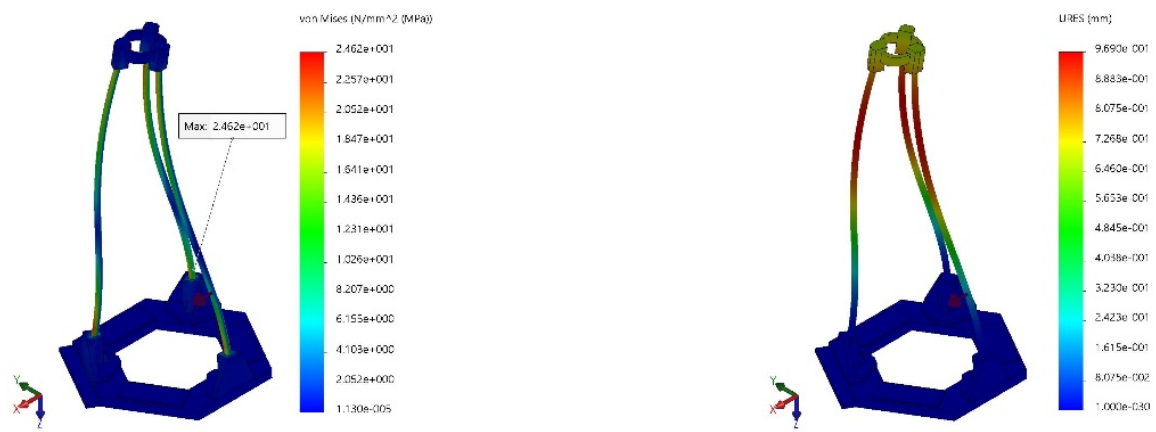

Figure 5. LIDAR vibration stress: X-axis. Figure 6. LIDAR vibration displacement: X-axis

Table 2. Results of the vibrational analysis: displacement and von Mises stress

\begin{tabular}{|c|c|c|c|c|c|}
\hline Displacement & $\begin{array}{l}\text { Minimum } \\
{[\mathrm{mm}]}\end{array}$ & $\begin{array}{l}\text { Maximum } \\
{[\mathrm{mm}]}\end{array}$ & $\begin{array}{l}\text { von Mises } \\
\text { Stress }\end{array}$ & Minimum [MPa] & $\begin{array}{c}\text { Maximum } \\
{[\mathrm{MPa}]}\end{array}$ \\
\hline Axis $\mathrm{X}$ & $1 \times 10^{-3}$ & $9.69 \times 10^{-1}$ & Axis $\mathrm{X}$ & $2.144 \times 10^{-5}$ & 25.62 \\
\hline
\end{tabular}

Table 2 shows that the structure is well fitted for the load requested, as no member presents excessive stress, which is an indicator that deformation will not occur. 


\subsection{Static analysis}

For the static analysis, it was used a refined mesh with 235372 elements and 373785 nodes. The boundary condition applied was a fixture, shown in Figure 7, in a small area of the base, and for the load conditions, a 5G force applied in the - y-direction, and another 5G force was applied in the - zdirection, as shown in Figure 8.

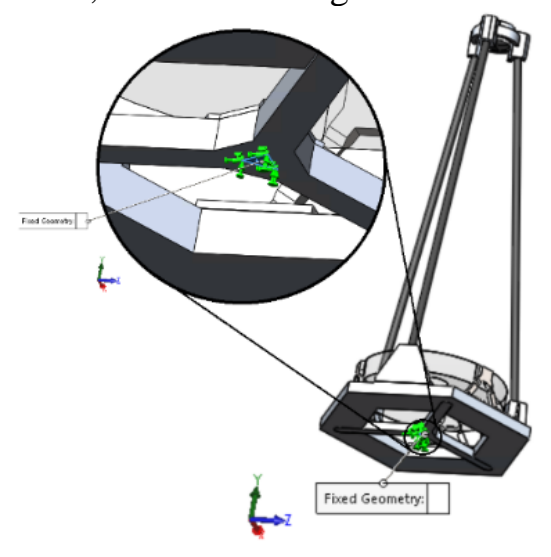

Figure 7. Boundary condition: Fixture.

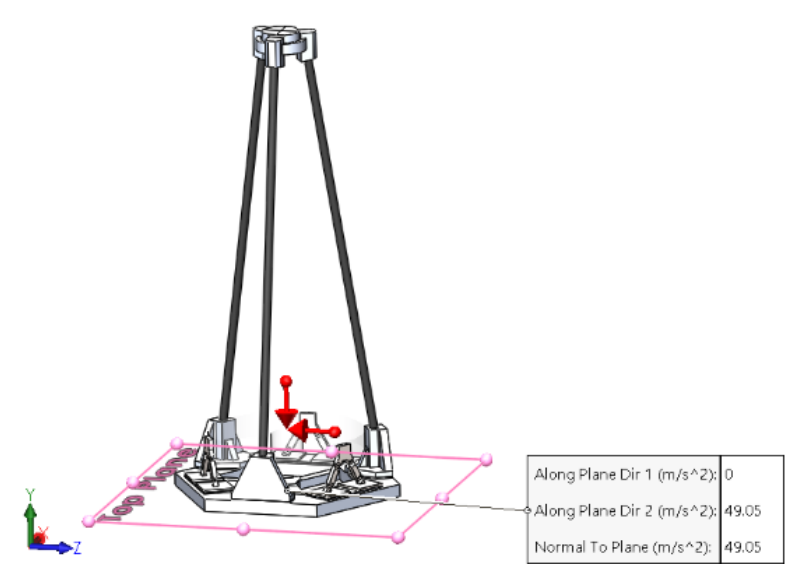

Figure 8. Boundary condition: Load.

The von Mises stress distribution was obtained for both studies, i.e., aluminium and titanium studies, and the maximum stress for the first study was $26.72 \mathrm{MPa}$, and it was observed in the area where the fixture was applied, given a safety factor value of 8.05. For the second analysis, the maximum stress was verified in the same area with a value of $32.13 \mathrm{MPa}$, with a safety factor value of 6.70 .

The secondary mirror's displacement with respect to the telescope baseplate was retrieved from the upper structure (blue line) in Figure 9.

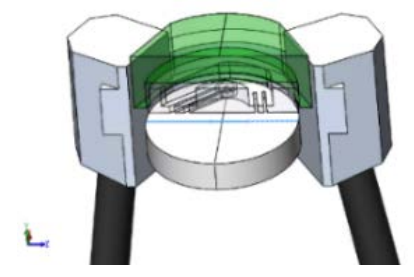

Figure 9. Secondary mirror upper surface.

The simulations provided two types of results: secondary mirror displacement, and secondary mirror surface deformation. Both studies are presented in Figure 10, to help the comparison.

Figure 10 (a) represents the secondary mirror's displacement when applied the $G$ forces (for the aluminium and titanium studies). Figure 10 (b) shows a comparison of the secondary mirror surface profile (i.e. before and after applied load conditions).

For the titanium study, the safety factor is lower, and regarding the deformation, the secondary mirror surface shows a slightly higher deformation, as can be seen in Figure 10 (a).

\subsection{Thermal analysis}

The LIDAR operational temperatures are $-40^{\circ} \mathrm{C}$ to $+60^{\circ} \mathrm{C}$. Thermal analysis of $-40^{\circ} \mathrm{C}$ was performed, where the reference temperature at zero strain was set to $24.85^{\circ} \mathrm{C}$. Note that in this case, the optical performance is a requirement; consequently, the optical tolerance analysis must be considered. For the temperature simulations the same mechanical model, as the Static Analysis, was used. 


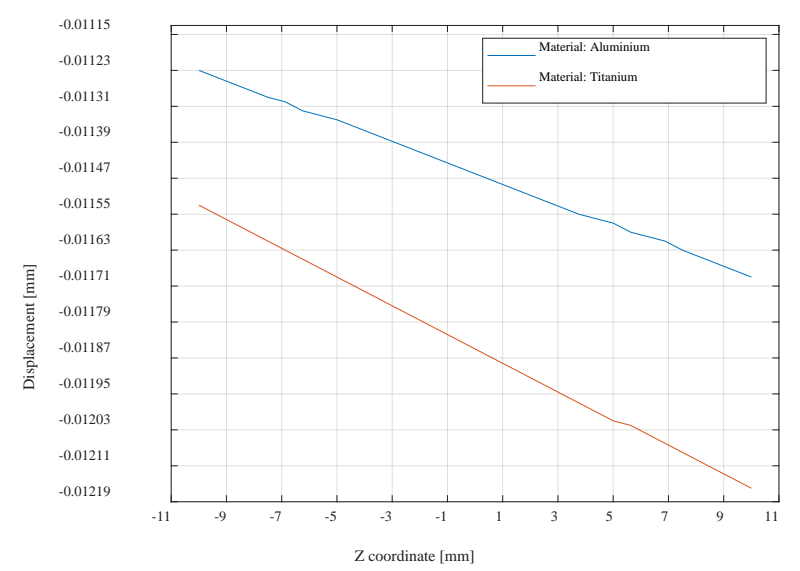

(a)

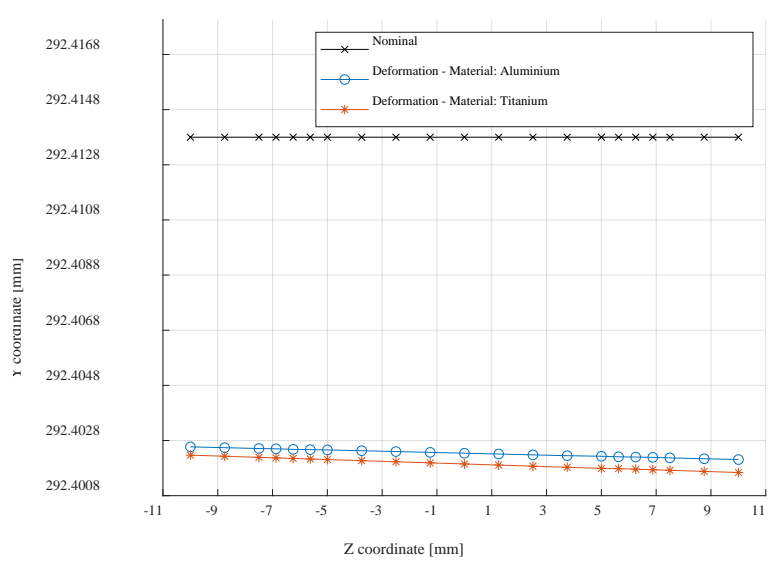

(b)

Figure 10. Static analysis: a) displacement, b) deformation.

Table 3 shows the von Mises stress distribution for the different upper structural material. When applied the titanium material, the component that suffers the maximum stress, is in the fixation area. When the aluminium is the chosen material, the maximum stress is verified in the GRV, the component that supports the secondary mirror.

Table 3. von Mises stress results, for $-40^{\circ} \mathrm{C}$

\begin{tabular}{|c|c|c|c|c|c|}
\hline \multicolumn{3}{|c|}{ Aluminium } & \multicolumn{3}{|c|}{ Titanium } \\
\hline $\begin{array}{c}\text { Maximum } \\
\text { stress [MPa] }\end{array}$ & SF & Component & $\begin{array}{c}\text { Maximum } \\
\text { stress [MPa] }\end{array}$ & $\mathrm{SF}$ & Component \\
\hline 206.9 & 1.04 & GRV & 180.1 & 1.19 & Fixation area \\
\hline
\end{tabular}

The secondary mirror displacement results when the telescope is at the temperature of $-40^{\circ} \mathrm{C}$ is presented in Figure 11 (a). The mirror surface profile variation is presented in Figure 11 (b). The values of the maximum displacement are compared with the tolerance analysis.

Regarding the thermal results, when the telescope was subjected to a temperature of $-40^{\circ} \mathrm{C}$, it suffered a contraction of $0.1101 \mathrm{~mm}$ when the upper structure was made of aluminum, and a contraction of $0.09454 \mathrm{~mm}$ for the titanium material. These values are compliant with the optical tolerance analysis.

\section{Conclusions}

During the LIDAR operative life the structure will be subject to a diverse range of environmental conditions: vibrations, accelerations, shocks, temperature variations.

Random vibration analysis is useful to verify if the structure can endure launch loads. In HERA mission ARIANE 6 is to be the launcher. Our simulations results concluded that the structure was not subjected to excessive stress, being an indication that permanent deformation will not occur.

Regarding the thermal-mechanical analysis, it can be concluded that when the telescope is subjected to the $\mathrm{G}$ forces, both materials can be an option, since in both studies the safety factor is high and deformation very low. However, for the thermal simulations, the best material for the telescope's upper structure, is titanium since the maximum stress and deformations are lower. 


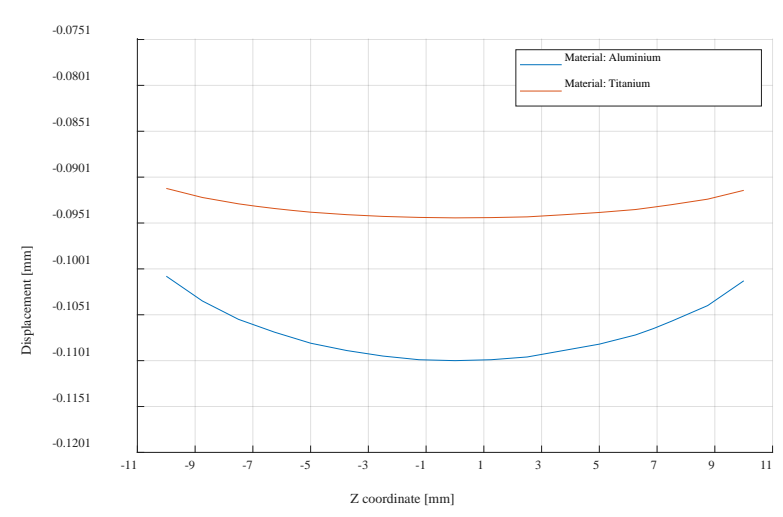

(a)

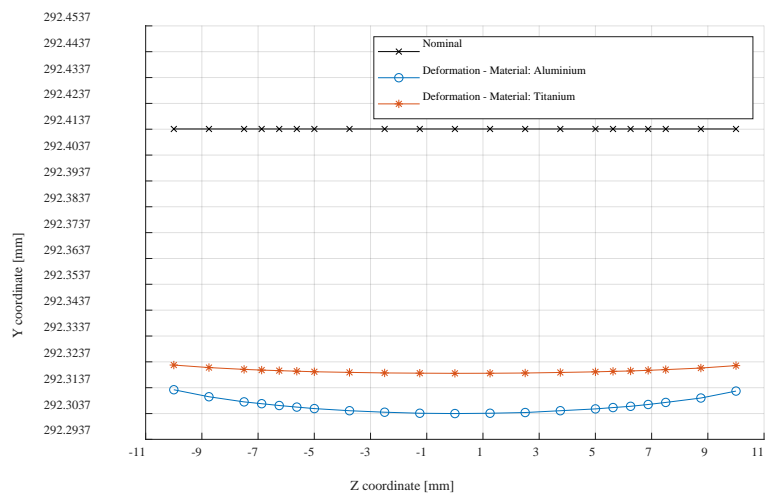

(b)

Figure 11. Negative temperature analysis: a) displacement, b) deformation.

\section{NEO-MAPP Team}

Karl Atkinson, Paula Benavidez, Jens Biele, Mélanie Drilleau, Colleen Fiaschetti, Sarah Fontaine, Alain Hérique, Martin Jutzi, Ozgur Karatekin, Julia de Leon, Javier Licandro, Naomi Murdoch, Danica Rémy, Grig Richter, Francisco da Silva Pais Cabral, Paolo Tortora, Kleomenis Tsiganis, JeanBaptiste Vincent, George Voyatzis, Kai Wuennemann, Marco Zannoni.

\section{Acknowledgment}

The ongoing work presented in this paper was financed by national funds through FCT (Foundation for Science and Technology, I.P.) through CENTRA, project UIDB/00099/2020; funding from the European Union's Horizon 2020 research and innovation programme under grant agreement No 870377 (project NEO-MAPP); funded through Foundation for Science and Technology (FCT) under the ICT (Institute of Earth Sciences) project UIDB/04683/2020; Portuguese Funds through the Foundation for Science and Technology (FCT) under the LAETA project UIDB/50022/2020.

\section{References}

[1] Shan, J., Toth, C. K., 2018, Topographic laser ranging and scanning principles and processing, CRC press.

[2] Gardner C. S. 1992 Ranging performance of satellite laser altimeters, IEEE Transactions on Geoscience and Remote Sensing 30(5) 1061-1072.

[3] Gordo P, Seixas D, Couto B, Amorim A, Melicio R, Marques A, Sousa T, Tezeremes G, Michel P, Kueppers M, and Carmelli I 2019 HELENA- Hera LIDAR engineering model altimeter design. Proc. 6th IAA Planetary Defense Conf., Washington, USA, pp. 1-6.

[4] Gordo P, Seixas D, Couto B, Amorim A, Livio B, Melicio R, Marques A, Sousa T, Granadeiro V, Pinto C, Tzeremes G, Michel P, Kueppers M, Carnelli I. 2019 HERA Lidar Instrument Development. Proc. 4th COSPAR Symp. Small Satellites for Sustainable Science and Development, Herzliya, Israel, pp. 1-6.

[5] Gordo P, Dias N G, Couto B, Arribas B N, Amorim A, Livio B, Melício R, Marques A, Sousa T, Granadeiro V, Michel P, Atkinson K, Benavidez P, Biele J, Drilleau M, Fiaschetti C, Fontaine S, Hérique A, Jutzi M, Karatekin O, de Leon J, Licandro J, Murdoch N, Rémy D, Richter G, Cabral F S P, Tortora P, Tsiganis K, Vincent J -B, Voyatzis G, Wuennemann K, Zannoni M. Planetary altimeter for HERA development, Proc. Europlanet Science Congress (EPSC) 2020, Göttingen, Germany, pp. 1-4. 